\title{
Flexible Control Strategy for Intelligent Building Air Conditioning System
}

\author{
Guiyuan XUE ${ }^{1 *}$, Chen WU11, Wenjuan NIU1 ${ }^{1}$ Xun DOU², Shizhen Wang ${ }^{2}$ and Yadie FU² \\ ${ }^{1}$ Economic Research Institute, State Grid Jiangsu Electric Power Co,.LTD, Nanjing, 210000, China \\ ${ }^{2}$ College of Electrical Engineering and Control Science, Nanjing TECH University, Nanjing, 211816, China
}

\begin{abstract}
An improved optimization adjustment strategy for building heating ventilation and air conditioning (Heating Ventilation and Air Conditioning, HVAC) is proposed. The energy consumption model of building heating/refrigeration is established by using the instantaneous energy balance of heat, and then the optimal operation strategy of building HVAC energy based on weather forecast data is constructed in the range of user temperature comfort. Finally, the MATLAB and TRNSYS simulation techniques are used to verify the example. Simulation results show that the optimal operation strategy of building HVAC energy based on weather forecast data can not only significantly reduce the cost of energy use, but also effectively improve the absorption capacity of renewable energy on the building side.
\end{abstract}

\section{Introduction}

With the rapid pace of urbanization in the world, the consumption of cities in energy consumption is soaring, and cities consume $75 \%$ of the world's energy. Among them, the total amount of building load in some big cities has exceeded the total electricity consumption of $40 \%$ of the cities[1-2].As the main body of energy consumption of building energy supply system, HVAC can effectively manage the energy consumption of intelligent building system and reduce the cost of building operation through direct control or price incentive measures.

At present, scholars at home and abroad have done a lot of research on intelligent control of buildings. In the aspect of modeling, the existing research can construct the virtual energy storage system model based on the building heat storage characteristics, and realize the charge and discharge management of the building virtual energy storage system[3-4].The dynamic model of heating / refrigeration energy consumption in intelligent buildings can also be constructed by using the heat transient energy balance equation and the energy management strategy of intelligent buildings based on model predictive control can be constructed[5-6].In the aspect of control, the existing research solves the problem of the deviation between prediction and real-time control by proposing a flexible control strategy of intelligent building energy use based on model predictive control[1].The optimal control model can be established based on the energy cost and user comfort, and the improved fast particle swarm optimization method is proposed[7].

To sum up, the existing research on the application of regular switching control methods to HVAC control has been very extensive. However, there are still many deficiencies in the traditional control method of HVAC. On the one hand, the relationship between user requirements and outdoor temperature changes has not been fully considered, on the other hand, the robustness of HVAC system is difficult to guarantee because of different conditions in different types of buildings. The energy consumption model of building heating/refrigeration is established by using the instantaneous energy balance of heat, and the dual-source switching strategy and the load migration strategy based on demand response are constructed in the range of user temperature comfort. Finally, the proposed strategy is verified by MATLAB and TRNSYS simulation technology.

\section{Smart Building Structure}

The energy flow diagram of intelligent building is shown in figure 1, which includes clean energy generation units. Air conditioning systems include air source heat pumps, gas boilers, electrical loads, heat loads, gas loads, and photovoltaic power generation.

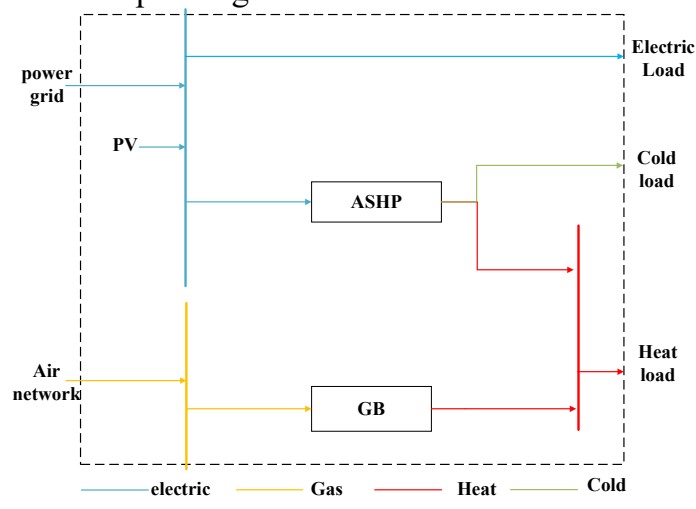

Figure 1. Energy flow diagram of intelligent building

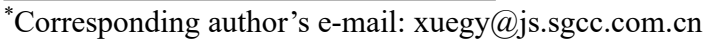


Energy transmission direction: building clean energy supply intelligent building internal consumption, winter by gas boiler and air source heat pump heating. The optimization object of this paper is a single intelligent building, which does not consider selling electricity to the power grid.

\section{Model Description}

\subsection{ASHP Energy cost estimation model}

Outdoor temperature and electricity price are the two most important factors affecting the cost of air source heat pump heating. The relationship between ambient temperature and COP values is as follows:

$$
C O P_{t}=0.0623 * \theta_{t}^{\text {out }}+3.16
$$

Cost of ASHP unit energy:

$$
\mathrm{C}_{\text {ASHP }}=\frac{\mathrm{C}_{\text {electritypice }}}{\mathrm{COP}_{\mathrm{t}}}
$$

Where, $\theta_{t}^{\text {out }}$ is ambient temperature. $\mathrm{C}_{\mathrm{ASHP}}$ is electricity price under given $C O P$ state. $\mathrm{C}_{\text {electritypice is }}$ power price for this period.

\subsection{Energy cost estimation model for gas-fired boilers}

Taking Beijing as an example, the price of natural gas is constant, so the efficiency of boiler is the only variable that affects its unit energy cost. The calculation formula of unit energy cost of gas boiler is as follows:

$$
\mathrm{C}_{\text {Boiler }}=\frac{\mathrm{C}_{\text {gasprice }}}{\eta \times 10.3}
$$

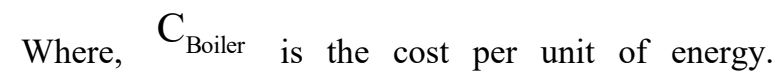
$\mathrm{C}_{\text {gasprice }}$ is the price of natural gas (2.98 yuan). $\eta$ is the working efficiency (0.9).

\subsection{Indoor temperature model}

The indoor temperature, the power of the air conditioning system and the outdoor temperature are the important factors affecting the temperature at this time in the process of building temperature change. The formula for calculating the temperature at each moment of the building is as follows:

$$
\begin{gathered}
\theta_{t}=\alpha_{1} \theta_{t-1}+\alpha_{2} p p_{t}+\alpha_{3} \theta_{t}^{\text {out }} \\
p p_{t}=p_{t}+p q_{t}
\end{gathered}
$$

Where, $p p_{t}$ is the power of air conditioning system. $\theta_{t}$ is indoor measured temperature ( $\left.{ }^{\circ} \mathrm{C}\right) .{ }^{2}, \alpha_{2}, \alpha_{3}$ are $0.95,0.5,0.06$ respectively. ${ }^{p_{t}}$ is the corresponding period of air conditioning system power. $p q_{t}$ is the corresponding period of air conditioning system gas power.

\subsection{Objective functions:}

By continuously controlling the power of the air conditioning system in the comfort temperature range (22$24^{\circ} \mathrm{C}$ ), the total power cost of the system is the lowest. The objective function is as follows:

$$
\min C=\sum_{t=1}^{T} \lambda_{t} p_{t}+\beta p q_{t}
$$

Where, $\mathrm{C}$ is the total cost of electricity in the working period. $\lambda_{t}$ is different periods of electricity price. $\beta$ is different periods of natural gas prices. $T$ is the working hours.

\subsection{Constraints}

Power upper and lower limit constraints for air conditioning systems:

$$
0 \leq p_{t} \leq p_{\max }
$$

Where, $p_{\max }$ is the maximum power of the air conditioning system.

Upper and lower limits of indoor temperature:

$$
\theta_{t}^{\min } \leq \theta_{t} \leq \theta_{t}^{\max }
$$

Where, $\theta_{t}^{\min }$ is the allowable minimum of indoor temperature $\left({ }^{\circ} \mathrm{C}\right)$ and $\theta_{t}^{\max }$ is the allowable maximum of indoor temperature.

Building power balance constraints:

$$
P V_{t}+P P_{t}=P_{t}+e l_{t}
$$

Where, $P V_{t}$ is roof photovoltaictel. $P P_{t}$ is total building power. $e l_{t}$ is electrical load other than air conditioning load.

\section{Building Air Conditioning System Control Strategy}

\subsection{Dual-source switching strategy}

The dual-source switching strategy is to divide different heating modes based on the unit energy cost of heating, as shown in formula (9):

$$
p p_{t}=\left\{\begin{array}{l}
p_{t}, C_{A S H P}<C_{\text {Boiler }} \\
p q_{t}, C_{A S H P}>C_{\text {Boiler }}
\end{array}\right.
$$

When the unit energy cost of air source heat pump is low, electric energy heating is chosen. Conversely, gas boiler heating is chosen. 


\subsection{Load migration strategy based on demand response}

Building is a complex energy system, building material, equipment capacity, solar radiation intensity, heat loss, outdoor environment, internal activities and so on, which has a great impact on the load transfer model (Load Shifting), etc. Based on the demand response load migration strategy, the HVAC system of buildings can be managed by transferring the load from the peak period to the off-peak period in the peak period, which can reduce the electricity charge in the peak period and alleviate the impact on the power grid.

\subsection{Dual-source switching strategy based on load migration}

Combining dual-source switching strategy with demandbased response load migration strategy can save energy consumption of buildings to a greater extent. The optimization process is shown in figure 2 .

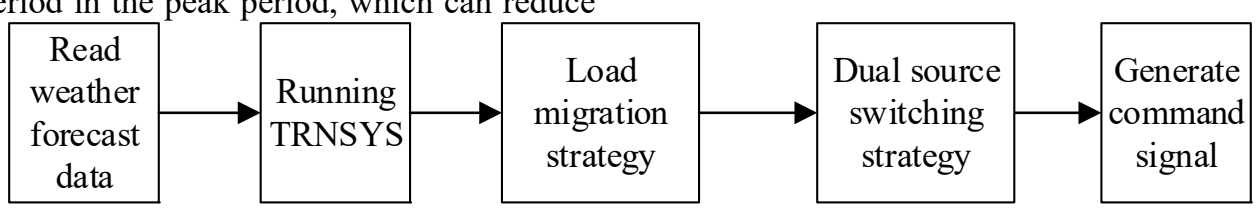

Figure 2. Flowchart of dual source switching strategy based on load migration

\section{Example Analysis}

\subsection{Basic data}

The simulation environment of this paper is as follows: housing area is $1000 \mathrm{~m}^{2}$, air density $=1.204 \mathrm{~kg} / \mathrm{m}^{3}$, air specific heat capacity is $1.012 \mathrm{~J} /\left(\mathrm{kg} \cdot{ }^{\circ} \mathrm{C}\right)$, atmospheric pressure is 101325.000(PA), water evaporation heat is $2454.0 \mathrm{k} / \mathrm{kg}$, air supply wind speed is $4 \mathrm{~m} / \mathrm{s}$.. The temperature curve starts from downloading and processing meteorological data, the running wget, downloads the data from the $\mathrm{CMC}$, and then uses the MATLAB call TRNSYS, to read the meteorological data running data for the next 24 hours. Building load and photovoltaic power generation are shown in figure 3.Electricity price information selects Beijing's industrial and commercial electricity price, as shown in figure 4 . The air price is 2.98 yuan $/ \mathrm{m}^{3}$, the building area is $150 \mathrm{~m}^{2}$, the maximum power of air source heat pump is $12 \mathrm{~kW}$.

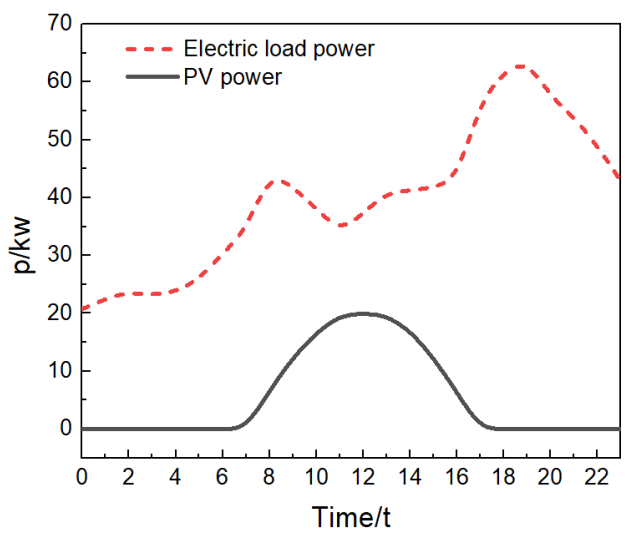

Figure 3. Building solar load and PV power

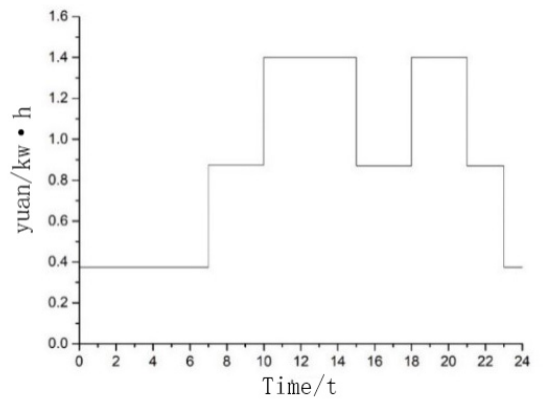

Figure 4. Electricity price information in Beijing

\subsection{Results Analysis of Dual-source Switching Strategy}

Choose the historical extreme value of Beijing in winter, take $-27.4^{\circ} \mathrm{C}$, combine peak and valley electricity price, gas price and outdoor temperature, divide the opening strategy of different time period, the result of division is shown in figure 5 . 


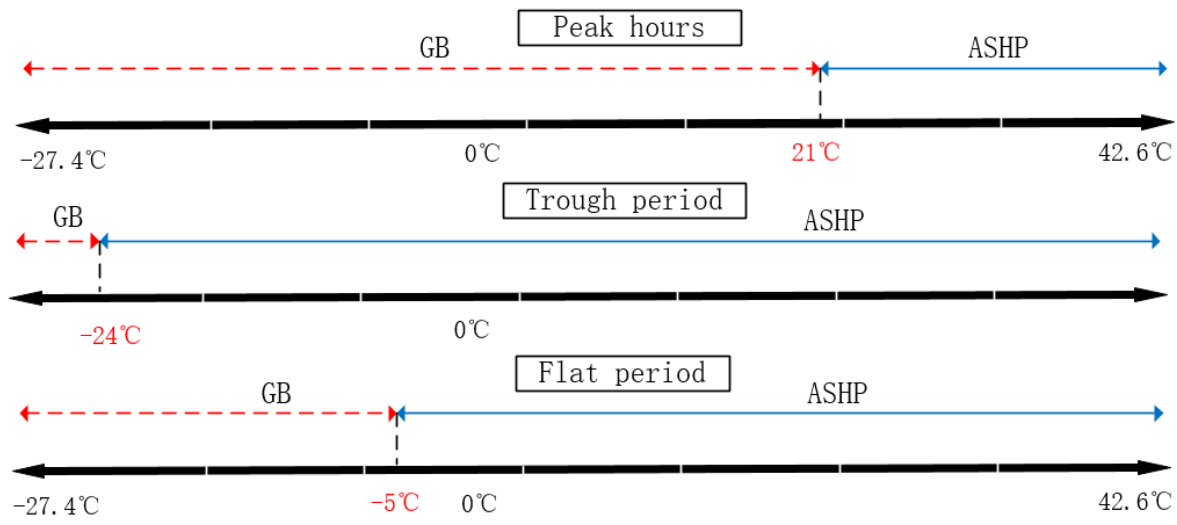

Figure 5. Resulit of dual-source switching strategy

Figure 4 shows that in the valley electricity period, because the electricity price is very low, unless the temperature reaches $-25^{\circ} \mathrm{C}$, there is no chance to open the gas furnace. At the normal period of electricity price, the dividing point is $-5^{\circ} \mathrm{C}$. During the peak period, the partition point is $28^{\circ} \mathrm{C}$, while heating is usually in winter, so in the peak period of electricity price, the cheaper gas boiler will be used for heating.

In order to verify the effectiveness of the two-source switching strategy proposed in this paper, a typical winter day temperature in Beijing is used for example analysis. Table 1 shows the energy cost at different dates, different outdoor temperature upper and lower limits. As can be seen, dual-source switching strategy is very effective for saving energy cost at very low outdoor temperature. On 2 January, for example, the average daily temperature was as low as $-12.55^{\circ} \mathrm{C}$, and the energy cost saved by the air conditioning system reached 25.55 per cent in one day, because the COP value of the ASHP decreased with the decrease of temperature, resulting in higher unit energy requirements. Therefore, in winter heating, air conditioning system selection of appropriate heating channels is very important for intelligent buildings to reduce the cost of air conditioning system.

Table 1. Comparison of the Dual-source Switching Strategy at Different Temperature Conditions

\begin{tabular}{cccccccc}
\hline \multirow{2}{*}{ Urban } & Date & $\begin{array}{c}\text { Average } \\
\text { temperatur } \\
\mathrm{e}\end{array}$ & $\begin{array}{c}\text { Maximum daily } \\
\text { temperature }\end{array}$ & $\begin{array}{c}\text { Daily minimum } \\
\text { temperature }\end{array}$ & Before & After & Savings \\
\hline \multirow{3}{*}{ Beijing } & December & -1.55 & 4.6 & -7.7 & 58.34 & 51.74 & $11.3 \%$ \\
& January & -12.55 & -6.8 & -18.3 & 49.56 & 36.90 & $25.6 \%$ \\
& February & 0.03 & 7.2 & -7.15 & 12.72 & 12.66 & $0.4 \%$ \\
\hline
\end{tabular}

\subsection{Results Analysis of Load Migration Strategy Based on Demand Response}

In order to verify the effectiveness of the demand response load migration strategy proposed in this paper, the temperature of a typical winter day (January 2) in Beijing is used for an example analysis. The simulation results are shown in figure 6.

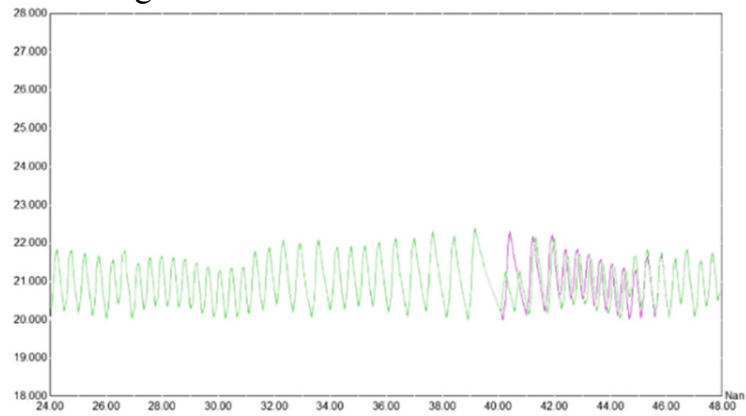

Figure 6. Comparison of temperature curves before and after optimization of dual source switching strategy
As can be seen from figure 6, the temperature drops to a very low level around 16:00 at room temperature, because the air conditioning system, in order to avoid the peak period of electricity price, chooses to minimize the power consumption of the air conditioning system within the range of user temperature comfort. However, the temperature curve before and after the strategy optimization meets the requirements of user comfort.

Figure 7 shows the comparison between the start and stop signals of the air conditioning, where 1 represents the opening of the air conditioning and 0 represents the closing of the air conditioning, and the other curve represents the price of electricity. It can be seen that the optimized HVAC start and stop signal avoids the peak period of electricity price, and reduces the power consumption cost from 49.56 yuan to 31.10 yuan on the premise of ensuring the temperature comfort of the user, which effectively reduces the energy consumption of air conditioning. 


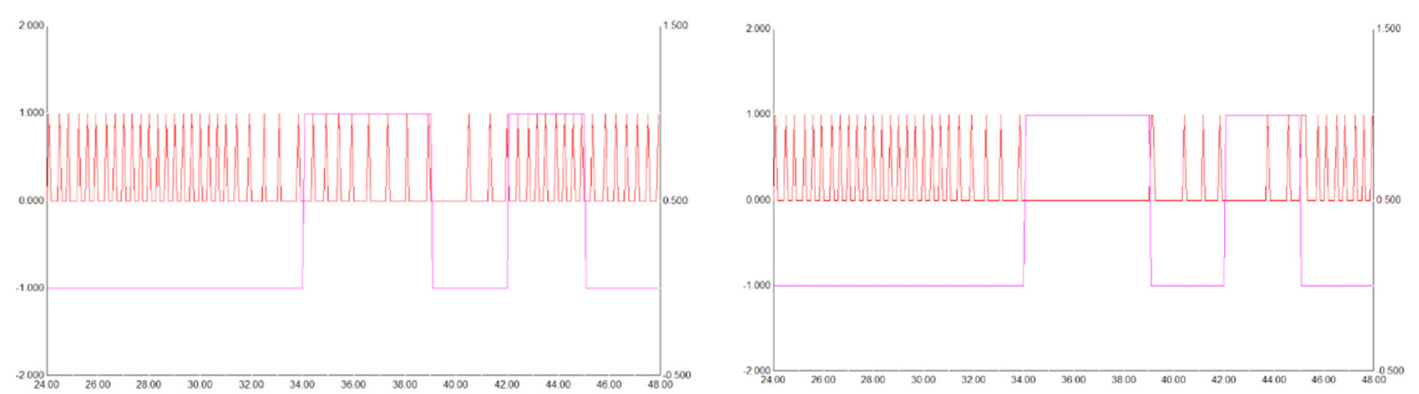

Figure 7. Comparison of air conditioning start stop signals before and after load transfer strategy optimization

\subsection{Analysis of optimization results of dual- source switching strategy based on load migration}

In order to verify the effectiveness of the two-source

Table 2. Two-source switching strategy optimization results based on load migration

\begin{tabular}{cccccc}
\hline Location & Date & $\begin{array}{c}\text { Average daily } \\
\text { temperature }\end{array}$ & $\begin{array}{c}\text { Cost before } \\
\text { optimization }\end{array}$ & $\begin{array}{c}\text { Cost of } \\
\text { optimization }\end{array}$ & Cost savings \\
\hline \multirow{3}{*}{ Beijing } & December & -1.55 & 818.34 & 794.18 & 24.16 \\
& January & -12.55 & 809.56 & 791.11 & 18.45 \\
& February & 0.02 & 772.72 & 771.69 & 1.03 \\
\hline
\end{tabular}

Because the proposed strategy only optimizes the building air conditioning system, and because of the large power load of the building, the saving cost can not obviously show the superiority of the proposed strategy. switching strategy based on load migration, the temperature curves of three typical winter days in Beijing are used to verify and analyze. Considering the influence of roof photovoltaic and building electric load, the optimization results are shown in Table 2.

Table 3 Optimization Results of Dual-source Switching Strategy Based on Load Migration II

\begin{tabular}{|c|c|c|c|c|c|c|c|c|c|c|}
\hline \multirow[b]{2}{*}{$\begin{array}{c}\text { Locatio } \\
n\end{array}$} & \multirow[b]{2}{*}{ Mon } & \multirow{2}{*}{$\begin{array}{l}\text { Avera } \\
\text { ge } \\
\text { daily } \\
\text { tempe } \\
\text { rature } \\
{ }^{\circ} \mathrm{C}\end{array}$} & \multicolumn{3}{|c|}{ Before optimization } & \multicolumn{3}{|c|}{ After optimization } & \multicolumn{2}{|c|}{ Optimal analysis } \\
\hline & & & $\begin{array}{c}\text { Consu- } \\
\text { mption } \\
\text { in peak } \\
\text { hours }\end{array}$ & $\begin{array}{l}\text { Consump- } \\
\text { tion in } \\
\text { peacetime }\end{array}$ & Cost & $\begin{array}{c}\text { Consu- } \\
\text { mption } \\
\text { during } \\
\text { peak } \\
\text { hours }\end{array}$ & $\begin{array}{l}\text { Consump- } \\
\text { tion in } \\
\text { peacetime }\end{array}$ & Cost & $\begin{array}{l}\text { Cost } \\
\text { saving } \\
\mathrm{s}\end{array}$ & $\begin{array}{c}\text { Saving } \\
\mathrm{s}(\%)\end{array}$ \\
\hline \multirow{3}{*}{ Beijing } & Dec & -1.55 & 24 & 42 & 58.3 & 3 & 48 & 34.2 & 24.2 & 41.4 \\
\hline & Jan & -12.6 & 18 & 45 & 49.6 & 0 & 51 & 31.1 & 18.5 & 37.2 \\
\hline & Feb & 0.02 & 3 & 21 & 12.7 & 3 & 19 & 11.7 & 1.0 & 8.1 \\
\hline
\end{tabular}

The simulation results show that by implementing the dual-source switching strategy based on load migration, the building energy management mode can:

1) can avoid the electricity price peak period without affecting the comfort, for example, in Beijing on December 2, in the non-peak period, air conditioning additional $6 \mathrm{kw} \cdot \mathrm{h}$, peak period reduced $21 \mathrm{kw} \cdot \mathrm{h}$, saving 24.16 yuan, effectively reducing the cost of energy use;

2) take Beijing February 2 as an example, if the external temperature is high, the peak period transfer is less, the air conditioning is basically closed, and there is no load migration. The lower the temperature, the more transfer. The higher the outdoor temperature, the higher the transferable load rate and the smaller the reverse.
Therefore, the air conditioning system of the building is analyzed separately, and the optimization results are shown in Table 3. 


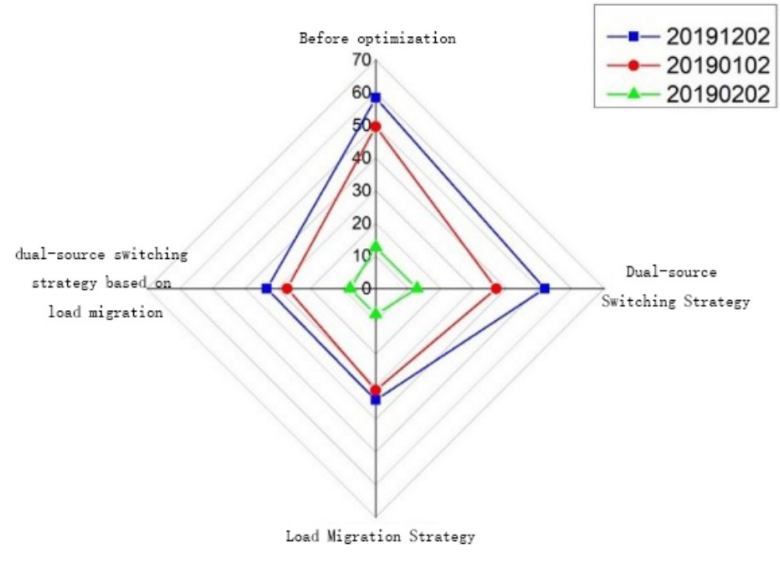

Figure 8 Comparison of the optimization results of the three optimization strategies proposed in this paper

As can be seen from figure 9, the three strategies play a great role in saving energy efficiency. The energy saving effect of the two-source switching strategy based on load migration is greatly improved compared with the first two strategies. However, in the case of very low outdoor temperature (December), the energy saving effect of load migration strategy based on demand response and load migration is not different.

\section{Conclusion}

This paper puts forward three strategies for energy saving of building air conditioning system, and draws the following conclusions:

- On the premise of not affecting the comfort of users, the cost of electric heating and heating is compared, and the more suitable heating mode is selected, which can effectively reduce the cost of building energy consumption, improve the level of building energy use and the level of renewable energy consumption;

- $\quad$ Based on the change of energy price, load transfer can reduce power grid overload and reduce user energy cost.

\section{Acknowledgments}

This work was supported by Science and technology projects of State Grid Jiangsu Electric Power Design Consulting Co., Ltd. (JE202003).

\section{References}

1. Wang Xudong, Wu Liping, Qi Yan, Ding Yi, Qi Fengyu, du Lijia. Energy Management Strategy for HVAC in Intelligent buildings based on Model Prediction Control [J].].1 Power system and its Automation ,2019,31(06):98-106.

2. A Survey and Analysis on the Present Situation and Trends of Building Energy Saving in China [J].] by Wu Yufu Low carbon World ,2017(17):151-152.

3. China Building Energy Saving Annual Development
Research Report of the 15th Tsinghua University Building Energy Saving Academic Week [J].] Construction Technology 2019(08):8.

4. Jin Xiaolong, Mu Yunfei, Jia Hongjie, Yu Xiaodan, Chen Naishi, GE Xianjun, Yu Jiancheng. Optimization scheduling method [J].] of Thermal and Hot ITU Energy Storage system for Building Microgrid by Fusion demand side Virtual Energy Storage system Chinese Journal of Electrical Engineering ,2017,37(02):581-591.

5. Wang Xudong, Wu Liping, Qi Yan, Ding Yi, Qi Fengyu, du Lijia. Energy Management Strategy for HVAC in Intelligent buildings based on Model Prediction Control [J].].1 Power system and its Automation ,2019,31(06):98-106.

6. Zhang Yan, Zhang Tao, Liu Yajie, Guo Bo. Study on Optimal Energy Management of Home Energy LAN Based on Model Prediction Control [J].]; Chinese Journal of Electrical Engineering, 2015, 35(14):36563666.

7. Amanda Abreu, Romain Bourdais, Herve Gueguen. Hierarchical Model Predictive Control for Building Energy Management of Hybrid Systems. 2018, 51(16): 235-240. 